\title{
Massive pleural effusion in ovarian tumor patient during laparoscopic surgery
}

\author{
Kyoung Hun Kim, Jang Won Byun, Gu Min Kwon, and Jae Hang Shim \\ Department of Anesthesiology and Pain Medicine, School of Medicine, Hanyang University, Guri, Korea
}

Laparoscopy is a recent widely used procedure when operating gynecologic diseases. Position change, increased intraabdominal pressure or pneumoperitonium can cause pleural effusion during the laparoscopic surgery. On the other hand, disease condition such as ovarian tumor is also associated with pleural effusion. Several ovarian tumors with pleural effusion and/or ascites are known as pseudo-Meigs syndrome [1]. We present such a case of right massive hydrothorax in a female patient with serous adenocarcinoma of ovary during laparoscopic gynecologic surgery.

A fifty eight years old woman, weighing $55 \mathrm{~kg}$ with $22.8 \mathrm{~kg} /$ $\mathrm{m}^{2}$ of body mass index, was admitted. Pelvic sonography and computed tomography scan exposed a $7 \mathrm{~cm}$ sized mass of right ovary sex-cord stroma tumor origin. Exploratory laparoscopy was scheduled. Hyperthyroidism was her only co-existing disease. Preoperative thyroid function test and laboratory blood tests were within the normal limits, serum albumin $(4.6 \mathrm{~g} / \mathrm{dl})$ and total protein $(7.6 \mathrm{~g} / \mathrm{dl})$ levels were also normal. CA-125 $(847.0 \mathrm{U} / \mathrm{ml})$ was elevated. Electrocardiography and echocardiography were nonspecific. Chest X-ray taken 2 weeks before surgery was normal and no evidences suggesting hydrothorax or pleural effusion was seen. The patient showed good general conditions and had no chest symptoms. Atropine sulfate $0.5 \mathrm{mg}$ and midazolam $2 \mathrm{mg}$ were given as premedication. During the induction period, her vital signs were stable and anesthesia was maintained at $\mathrm{O}_{2} 2 \mathrm{~L} / \mathrm{min}, \mathrm{N}_{2} \mathrm{O} 2 \mathrm{~L} / \mathrm{min}$, desflurane $5 \mathrm{vol} \%$, and remifentanil. Measured peak airway pressure $\left(\mathrm{P}_{\mathrm{aw}}\right)$ and end-tidal $\mathrm{CO}_{2}$ concentration $\left(\mathrm{ETCO}_{2}\right)$ were $19 \mathrm{cmH}_{2} \mathrm{O}$ and $30 \mathrm{mmHg}$. After position changing to Trendelenburg and abdominal insuf- flation with $\mathrm{CO}_{2}, \mathrm{P}_{\mathrm{aw}}$ and $\mathrm{ETCO}_{2}$ increased to $23 \mathrm{cmH}_{2} \mathrm{O}$ and 35 $\mathrm{mmHg}$. Forty minutes after the incision, BP, $\mathrm{ETCO}_{2}$ and $\mathrm{SpO}_{2}$ suddenly decreased to $75 / 50 \mathrm{mmHg}, 17 \mathrm{mmHg}$ and $96 \%$, respectively. Ephedrine $10 \mathrm{mg}$ was injected and arterial blood gas analysis (ABGA) showed $\mathrm{PaO}_{2} 92 \mathrm{mmHg}, \mathrm{PaCO}_{2} 29 \mathrm{mmHg}$, and $\mathrm{pH} 7.44$ in $\mathrm{FiO}_{2}$ of 0.5 . Immediate verification for tracheal secretions was negative, but right side lung sound was slightly decreased. $\mathrm{N}_{2} \mathrm{O}$ was stopped and $\mathrm{SpO}_{2}$ became $100 \%$ within a few minutes in $\mathrm{FiO}_{2}$ of 1.0. One hour later, $\mathrm{ABGA}$ showed $\mathrm{PaO}_{2} 83 \mathrm{mmHg}, \mathrm{PaCO}_{2} 33 \mathrm{mmHg}$, and $\mathrm{pH} 7.39$ in a $\mathrm{FiO}_{2}$ of 1.0. Ventilator parameters and other vital signs were stable until the end of surgery. Laparoscopic hysterectomy with bilateral salpingo-oophorectomy, partial omentectomy was performed for 3 hours without any other events. The pathological diagnosis of the tumor was $8.5 \times 6.4 \mathrm{~cm}$ sized serous adenocarcinoma. Packed red blood cell of 2 pints, Ringer's lactate $(650 \mathrm{ml})$ and hydroxyethyl starch (voluven ${ }^{\circledR}$, Fresenius Kabi, Bad Homburg, Korea) $(1000 \mathrm{ml})$ were given, checked urine output and blood loss were $180 \mathrm{ml}$ and $1000 \mathrm{ml}$ during surgery. After extubation, her breathing was normal and no signs of difficulty were seen. Forty minutes later at the post anesthesia care unit (PACU), $\mathrm{SpO}_{2}$ and $\mathrm{PaO}_{2}$ fell down to $94 \%$ and $94 \mathrm{mmHg}$ in a $\mathrm{FiO}_{2}$ of 0.5 with venturi mask, the chest radiography taken at this time showed diffuse haziness and pleural space widening on the right hemithorax (Fig. 1). Lasix $10 \mathrm{mg}$ was given and thoracic surgeon inserted a chest tube. Chest tube position was verified and its drainage was about $1500 \mathrm{ml}$. ABGA of 1 hour after the tube insertion was $\mathrm{PaO}_{2} 204$ mmHg, $\mathrm{PaCO}_{2} 35 \mathrm{mmHg}$, and $\mathrm{pH} 7.42$ in a $\mathrm{FiO}_{2}$ of 0.5 and vital signs were stable. On the $7^{\text {th }}$ day after the tube removal, ABGA

Corresponding author: Jae Hang Shim, M.D., Ph.D., Department of Anesthesiology and Pain Medicine, School of Medicine, Hanyang University, 249-1, Gyomun-dong, Guri 471-701, Korea. Tel: 82-31-560-2396, Fax: 82-31-563-1731, E-mail: jhshim@hanyang.ac.kr

(c) This is an open-access article distributed under the terms of the Creative Commons Attribution Non-Commercial License (http:// creativecommons.org/licenses/by-nc/3.0/), which permits unrestricted non-commercial use, distribution, and reproduction in any medium, provided the original work is properly cited. 


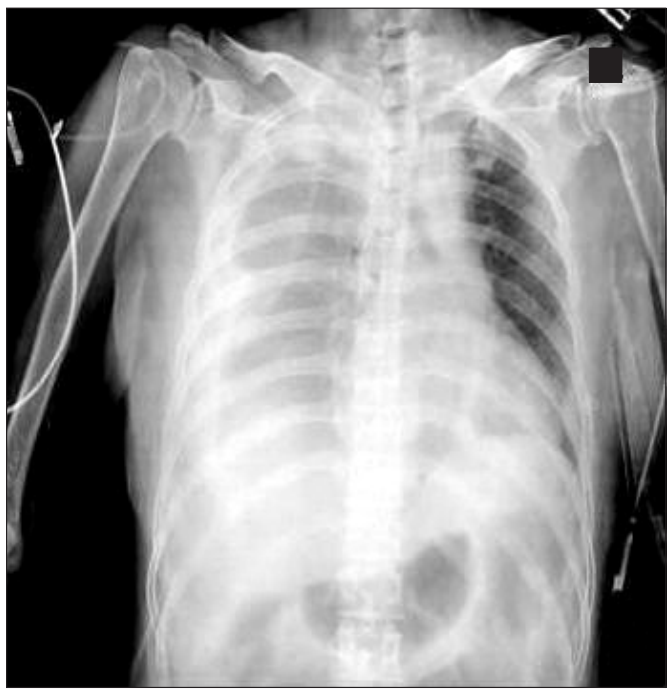

Fig. 1. Chest radiograph shows diffuse haziness and pleural space widening on the right hemithorax at PACU after surgery.

was $\mathrm{PaO}_{2} 97 \mathrm{mmHg}, \mathrm{PaCO}_{2} 38 \mathrm{mmHg}$, and $\mathrm{pH} 7.43$ in room air. The chest X-ray showed both clear lung field and no evidence of hydrothorax or pleural effusion, and the patient did not exhibit any abnormal respiratory or chest symptoms.

Several hypotheses have been advanced to explain the formation of the ascitic fluid or pleural effusion, including mechanical irritation of the peritoneum by either a massive tumor, the venous and lymphatic congestion of the tumor itself or even the decrease of albumin [2]. In our case, the serum albumin was normal. However, tumor size was $8.5 \times 6.4 \mathrm{~cm}$ and the massive mass may have caused the formation of pleural effusion. Meigs and Cass [3] described the clinical condition that was the occurrence of a pleural effusion together with ascites and an ovarian fibroma or fibrothecoma in 1937. Patients with pseudo-Meigs' syndromes complained of significant non-cardiopulmonary conditions presented with dyspnea and wheezing [4]. High stage ovarian cancer or cancer antigen-125 (CA-125) also revealed the relation to pleural effusion. Abnormal serum levels of CA125 were found in $76 \%$ of all patients with ovarian malignancies and in $87 \%$ of patients with pleural effusion. High serum CA125 levels are closely correlated with peritoneal extension of the disease [5]. We should have paid careful attention to evaluations for pleural effusion because the patient's CA-125 level was high. There are no routine indications to obtain a chest radiograph in preoperative evaluations. The chest radiograph should be used to assess concerned abnormalities that are present by history or physical examination. We usually check the chest radiography routinely before operation. However, it is unclear whether an accurate assessment of intrathoracic disease and the extent of pleural involvement can be made from radiographic studies alone. In this case, chest X-ray was taken 2 weeks before surgery and no evidence suggesting hydrothorax or pleural effusion was seen. Nevertheless, we could not exclude the possibility that ascites or pleural effusion developed within 2 weeks before operation and becomes more aggravated during the operation.

In our case, it is possible that the right-sided hydrothorax seems to be linked to the laparoscopic approach, and can be explained by the cumulative effects of the Trendelenburg positioning over time and the pneumoperitoneum. Pelvic malignancy itself may also be another cause. With high level of CA-125 and possible pleural metastasis, pseudo-Meigs' syndromes seem to be related to pleural effusion. It is important for anesthesiologist to consider pleural effusion associated with pelvic malignancy during laparoscopic surgery, although there is no significant change in chest X-ray or symptomes such as dyspnea.

\section{References}

1. O'Flanagan SJ, Tighe BF, Egan TJ, Delaney PV. Meigs' syndrome and pseudo-Meigs' syndrome. J R Soc Med 1987; 80: 252-3.

2. Agranoff D, May D, Jameson C, Knowles GK. Pleural effusion and a pelvic mass. Postgrad Med J 1998; 74: 265-7.

3. Meigs JV, Cass JW. Fibroma of the ovary with ascites and hydrothorax. Am J Obstet Gynecol 1937; 33: 249-67.

4. Hahm TS, Ham JS, Kang JY. Unilateral massive hydrothorax in a gynecologic patient with pseudo-Meigs' syndrome -A case report-. Korean J Anesthesiol 2010; 58: 202-6.

5. Topalak O, Saygili U, Soyturk M, Karaca N, Batur Y, Uslu T, et al. Serum, pleural effusion, and ascites CA-125 levels in ovarian cancer and nonovarian benign and malignant diseases: a comparative study. Gynecol Oncol 2002; 85: 108-13. 